NBER WORKING PAPER SERIES

\title{
WHO BEARS THE BURDEN OF SOCIAL INSURANCE?: \\ EVIDENCE FROM JAPANESE HEALTH \& LONG-TERM CARE INSURANCE DATA
}

\author{
Kohei Komamura \\ Atsuhiro Yamada \\ Working Paper 10339 \\ http://www.nber.org/papers/w10339 \\ NATIONAL BUREAU OF ECONOMIC RESEARCH \\ 1050 Massachusetts Avenue \\ Cambridge, MA 02138 \\ March 2004
}

The views expressed herein are those of the authors and not necessarily those of the National Bureau of Economic Research.

(C)2004 by Kohei Komamura and Atsuhiro Yamada. All rights reserved. Short sections of text, not to exceed two paragraphs, may be quoted without explicit permission provided that full credit, including (C) notice, is given to the source. 
Who Bears the Burden of Social Insurance?:

Evidence from Japanese Health \& Long-term Care Insurance Data

Kohei Komamura and Atsuhiro Yamada

NBER Working Paper No. 10339

March 2004

JEL No. J0, H0

\begin{abstract}
Using the society-managed health insurance data, which is cross-sectional time-series and covers 1,670 health insurance societies for seven years (FY1995-2001), we found for the first time in Japan that the majority of the employer's contribution to health insurance is shifting back onto the employees in the form of wage reduction. On the other hand, we cannot find such evidence for the contribution to long-term care insurance using a two-year (FY2000-01) panel data set.
\end{abstract}

\author{
Kohei Komamura \\ Associate Professor of Social Policy \\ Faculty of Economics \\ Toyo University \\ 5-28-20 Hakusan, Bunkyou-ku \\ Tokyo 112-8606 \\ Japan \\ bzr05433@nifty.ne.jp \\ Atsuhiro Yamada \\ Assistant Professor of Social Policy \\ Faculty of Economics \\ Keio University \\ 2-15-45 Mita, Minato-ku \\ Tokyo 108-8345 \\ Japan \\ atsuhiro@econ.keio.ac.jp
}




\title{
Who Bears the Burden of Social Insurance? :
}

\section{Evidence from Japanese Health \& Long-term Care Insurance Data}

\author{
Kohei KOMAMURA
}

Atsuhiro YAMADA

\section{Introduction}

1. As the population ages, social expenditure has been rapidly increasing in Japan as in other OECD countries. Social security in Japan is mainly based on social insurance schemes; health insurance, pension, long-term care insurance, unemployment insurance, and work injuries insurance. The first three insurances cover the entire population and the other two cover all employees in Japan.

2. The contributions to these insurances are shared by both employers and employees and the proportion of the share is legislated by the government. Social insurance contributions levied on employers were around 28.6 billion yen in FY2001. As shown in Figure 1, this is equivalent to some $5.7 \%$ of the $\operatorname{GDP}^{1}$ and is the largest resource to finance social security in Japan.

[Figure 1: Social Security Revenue by source, FY1980-2001]

3. Increasing burdens of social insurance shared by employers raises effective labour costs. This can shift forward to the product price, reduce employment, or shift backward to the employees by means of wage reduction. Especially concerns about reduction in employment lead to the assertion that the statutory burdens of social insurance levied on employers should be reduced and instead employees should pay more $^{2}$.

\footnotetext{
${ }^{1}$ The National Institute of Population and Social Security Research (2003) The Cost of Social Security FY2001.

${ }^{2}$ For example, Hiroshi OKUDA, the chairman of Japan Business Federation (Nippon Keidanren) insists in January 2003: "We call for a reduction or an abolishment of the
} 
4. However, as the well-known discussion of "tax incidence" in the economics field suggests, it is meaningless to discuss the statutory contribution rate of employers and employees in terms of its effective share rate, because it is determined by the elasticity of labour demand and supply.

5. Additionally, with respect to social insurance, this view can be modified, if employees realize the contribution as a reasonable counter value of social benefit. Then, the employees may agree to pay the full cost of social insurance out of their wage regardless of the statutory contribution rate.

6. In this paper, we explored to what extent the employees bear the cost of employers' contribution on top of their own contribution, using the cross-sectional timeseries data on health insurance societies in Japan.

\section{Conceptual Framework}

\subsection{Incidence of Social Security Contribution ${ }^{3}$}

7. It is well known that the standard partial equilibrium analysis of the tax incidence suggests that the employment or real wage rate is unrelated to how the social insurance contribution is statutorily shared by employers and employees.

8. Suppose that the equilibrium point before the introduction of social insurance is A. Consider the case where the social contribution is now introduced and its statutory contribution rate is set at $t_{f} \%$ of wage rate $W$ to employers by legislation. This is a kind of pay-roll tax. In this case, the labour demand curve will shift to the left side, and the labour demand will decline. The new equilibrium point is now on $B$.

[Figure 2: The Incidence of Social Insurance Contribution]

9. Summers (1989) modified this basic framework of tax incidence, taking account of the relationship between social insurance contribution and benefit. With respect to

Social security contribution paid by employers. Employees must pay the social security cost in full."

${ }^{3}$ We owe the explanation here to Filer, R., D. Hamermesh and A. Rees (1996). 
Health Insurance, contributions are directly proportional to benefits in the short-run. It means that the contribution is more strictly connected to a current benefit (e.g. health services) compared with other insurances; pension and long-term care insurance. This implies that employees are more likely to regard the benefit as an increase of effective wage. Thus, the labour supply curve will shift to the right side up to $t_{f} \%$ of nominal wage and then the new equilibrium point will be on $C$, not on $B$. The degree of these shifts depends on how employees value the current benefit, and therefore, is a matter of empirical analysis.

10. Most of the empirical analysis in the past found that the employees bore, at least, some part of the burden of employers' contributions to social insurance or payroll-tax. For example, Holmlund (1983), using Swedish time-series data for 1950-79, showed that a half of payroll-tax had been shifted back to wages. Gruber \& Krueger (1991) also concluded that contributions by employers to Workers' Compensation Insurance had been shifted back to the insured (employees) in the form of wage reduction, based on industry level data in the United States. Using the data derived from a census of manufacturing plants in Chile, Gruber (1997) showed that the reduction of payroll tax, which was introduced by the privatization of social security in 1981, was shifted back onto the employees' side. Additionally, Anderson \& Meyer (2000) investigated the effect of an introduction of experience-rated tax for Unemployment Insurance in Washington. According to their findings based on individual level earnings data, after the introduction in 1985, the firms with a high risk of unemployment have had to face a high tax rate and these additional costs have shifted onto their employees in the form of earnings reduction.

11. Contrary to these findings, Tachibanaki \& Yokoyama (2001), using the industry level time-series data in Japan for 1970-97, concluded that employers' contribution to social insurance was not shifted back onto employees at all. This leads us to the question of whether Japan provides a special case in terms of the incidence of social security contribution paid by the employers. 


\subsection{Description of Health and Long-term Care Insurance in Japan}

12. In this paper, we used the data collected on an annual basis by the National Federation of Health Insurance Societies (Kenporen). Before explaining the details of our data sets, it will be desirable to explain the role of health insurance societies and their position in the whole health insurance system of Japan, and related insurances (e.g. longterm care insurance).

13. Medical services in Japan are financed through a compulsory health insurance system. The system has been universal since 1961 and is organized on an occupational or regional basis. The former can be classified into three insurances; (1) Governmentmanaged health insurance, (2) Society-managed health insurances, and (3) Mutual aid associations; the latter is managed by (4) municipal governments. Around 30\%, 25\%, $10 \%$, and $35 \%$ of the entire population is covered by each type of health insurance respectively. The data set used in this paper is of the second type of health insurance: society-managed health insurance.

\section{[Figure 3: Major Public Health Insurances in Japan]}

14. Society-managed health insurances are organized on the basis of relatively largesized companies, and they provide medical services to both regular workers and their families. According to the Health Insurance Law, the legal status of societies is a sort of the under agent of the government. Non-regular workers are excluded from the society membership and have to be covered by the other type of public health insurance unless their working hours exceed three fourths of regular workers.

15. The contribution rates are set to cover the expenses of the medical services within a society-managed health insurance and the assessed contribution to the health service system for the aged. To some extent, the latter redistributes the financial resources all over the different types of health insurances to adjust the different dependency ratio in each health insurance.

16. The contributions to Society-managed health care insurances are income-related. Or more precisely, it is set as a percentage of monthly remuneration rather than wage rate. 
The formula for calculating a contribution rate in each society is; total expenditure of the society divided by total monthly remuneration paid to the insured workers covered by the society. The legislation requires sharing the contribution by employers and employees equally (e.g. $50 \%$ of the total contribution rate per each); however, the proportion of the share can be changed under a collective agreement. Then, in practice, the contribution rate for the employees or the employer is calculated by the formula; the monthly remuneration multiplied by the contribution rate, and multiplied by the employees' or employer's share of the contribution (not necessarily 50\%).

17. Mandatory long-term care insurance was introduced in April 2000. It is also financed by the contribution from employees aged over 40 who are covered by health insurance and their employers.

\subsection{Theoretical Analysis}

18. In this section, we explained our model based on Gruber (1997). Consider that labour demand and supply can be expressed by the following forms

labour demand; $L_{d}=f_{d}\left(W \times\left(1+t_{f}\right)\right)$,

labour supply; $L_{s}=f_{s}\left(W \times\left(1-a \times t_{e}\right)+q \times W \times t_{f}\right)$,

where

$W=$ the wage before the deduction for contribution to health insurance society;

$t_{f}=$ the contribution rate to health insurance society shared by employers;

$t_{e}=$ the contribution rate to health insurance society shared by employees;

$q=$ the extent to which employees value the employers' contribution relative to the benefits provided under the society-managed health insurance $(0<q<1)$; and

$a=$ the extent to which employees discount their contributions relative to the benefits provided under the society-managed health insurance $(0<a<1)$.

19. The parameter $a$ takes 1 , if the employees regard their contributions as income tax. At the other extreme, it takes 0 , if they regard their contribution as a counter value of the benefits to them. Solving this model, we obtain the equilibrium condition: 


$$
\frac{d W}{W} / d t_{f}=\frac{\eta^{s} \times q-\eta^{d}}{\eta^{d}-\eta^{s} \times\left(1-a \times t_{e}\right)}
$$

where $\eta$ is an elasticity of labour demand or supply. When the labour supply curve is vertical or when the elasticity of the labour supply is extremely small relative to the elasticity of the labour demand; the partial differentiation takes a value close to -1 .

20. Concerning the combination of parameter $q$ and $a$, there are four extreme cases. The first case is both parameters take value 0 . In this case, employees do not value the employers' contribution at all, but do value their contributions fully as a counter value of the benefits provided by the health insurance society. The second case is the parameter $q=0$ and $a=1$. In this case, employees do value neither their contributions nor their employer's contribution at all, as if aggregated contributions are a kind of income tax or pay-roll tax. The third case is the parameter $q=1$ and $a=0$, and it is the opposite case of the second. Employees fully value both employees' and employer's contributions, as if it is a price of private health insurance policy. The last case is the parameter $q=1$ and $a=1$. Here, employees do not value their contributions at all, but do value their employer's contribution fully as a counter value of the benefits provided by the society.

21. In the third case $(q=1$ and $a=0)$, note that:

$$
\frac{d W}{W} / d t_{f}=-1
$$

As the $q$ increases, the value noted the above will increase. Then, the equation for our econometric analysis will be:

$$
W=f\left(t_{f}, X\right)
$$

and our interest is on how the $W$ is affected by the change of $t_{f}$, controlling the individual characteristics: $X$.

22. A debatable point of applying this model to our analysis is that the amount of the health care services is irrelevant to the wage level of the beneficiaries and therefore 
the amount of contributions, because that is usually determined by a seriousness of the illness or injuries. However, the health insurance society provides not only the health care services but also the sickness allowance, which is equivalent to $60 \%$ of the beneficiaries' current wages. This allowance will be paid up to 18 months $^{4}$ and the regional-based health care insurance de facto does not have this allowance. Therefore, the benefit provided by the society-managed health care insurance is more likely to have a strong connection to the contribution.

23. Taking account of this aspect of society-managed health care insurance in Japan, the third case could be applied. Moreover, the benefit would be easily realised by the employees as the society is organized on the basis of the corporations and able to provide additional benefits independently.

24. Although long-term care insurance covers employees aged 40 and over, the main beneficiaries are people aged 65 and over. Therefore, in terms of the long-term care insurance, the second case, where the employees do not regard their contributions as a counter value of long-term care benefits, seems to be applied.

25. According to the simple model, we expect to observe a (statistically) significant and relatively large effect of the changes in $t_{f}$ on the wages for societymanaged health insurance even if some of the contributions are used for aged people to some extent, but not for the long-term care insurance.

\section{Data and Empirical Framework}

\subsection{Data sets and their limitations}

26. For our empirical analysis, we used Present Status Report on Societymanaged Health Insurances (Kenko Hoken Kumiai no Gensei), and Annual Report on Society-managed Health Insurance (Kenko Hoken Kumiai Jigyo Nenpo). Both reports are published by the National Federation of Health Insurance Societies, and they cover

\footnotetext{
${ }^{4}$ After 18 months, which is the maximum payment duration of the sickness allowance, the disability employees' pension will support the income of workers under the medical treatment.
} 
the many kinds of variables related to the theoretical model explained in the above: health insurance contribution rate for employer and employees, long-term care insurance contribution for employer and employees, numbers of the insured employees (regular workers) covered by society-managed health insurance and by long-term care insurance, average age of the insured, and the average monthly remuneration (bonuses are excluded) by each society-managed health insurance.

27. Based on both reports, we constructed cross-sectional and time-series data (panel data) sets, which cover from FY1995 to 2001. As the introduction of long-term care insurance was in April 2000, the data set related to variables of long-term care insurance ${ }^{5}$ becomes two-year panel data. The seven-year panel data set has 16, 690 observations of 1,670 health insurance societies, and the two-year panel data set has 3,286 observations of 1,643 health insurance societies. See the appendix for the key statistics of these two data sets.

28. The data cover only the insured persons and the related variables in our data are based on these persons. The temporary workers or part-time workers are not covered by the society-managed health insurance even if they work in the same corporation of the insured, and the variables related to them are not available. Thus, this data limitation restricts our analysis of incidence on wages only, rather than on both wages and employment.

\subsection{Empirical Framework}

29. As we discussed in section 2.3, we estimate the wage equation to investigate the effect of employers' contribution rate on monthly average remuneration. According to the theoretical framework, we should expect a negative co-efficient for the employers' contribution rate. Consider the fitting wage equation of the form

\footnotetext{
${ }^{5}$ There are two unavailable variables in the original report, which are related only to the long-term care insurance. The average age of the insured of long-term care insurance is not available. We reuse the same variable of the health insurance. The second variable is the share of contribution rate, which is paid by the employer. To obtain the equivalent variable of health insurance, we make an assumption that the total contribution rate is shared in the same proportion of the health insurance by employers. This is the reason we had to analyze the health insurance and the long-term care insurance separately.
} 


$$
w_{i t}=\alpha+x_{i t} \beta+v_{i}+\varepsilon_{i t}
$$

where

$w_{i t}=$ average monthly remuneration ${ }^{6}$ of the insured covered by the health insurance society $(i)$ in the year $(t)$ deflated by the wage index to remove the macro economic shock on wages;

$x_{i t}=$ average age of the insured, employer's contribution rate $(\%)$, and a number of insured employees $(\ln )$, by the health insurance society $(i)$ in the year $(t)$;

$v_{i}=$ the unit-specific residual of each health insurance society $(i)$; and

$\varepsilon_{i t}=$ the usual residual with the usual properties (mean 0 , uncorrelated with itself, uncorrelated with $x$, uncorrelated with $v$, and homoskedastic).

30. The number of insured employees included in $x_{i t}$ is a proxy variable of the firm size. As the past researche on Japanese wage profile suggested that the firm size is an important determinant of wage level, we put this variable into our wage equation.

31. An important institutional change during the observed period is that the copayment rate of the Society-managed Health Insurance was raised by the government from $10 \%$ to $20 \%$ in FY 1997 . This change would reduce the attractiveness of the benefit by the society, and the insured might have given lower evaluations on their employers' contributions to the society since FY1997. Therefore, we put a dummy variable to allow for differences in slope coefficient of the employer's contribution rate in $x_{i t}$ as well.

32. A choice of possible estimation model of the above is (1) pooled OLS model, (2) random-effects model, or (3) fixed-effects model. We do not know whether the unit-specific residual of each health insurance society actually exists or whether it correlated with independent variables, and therefore we can not identify which empirical model should be applied a priori. We will check the existence of unitspecific residual by the Breusch-Pagan Lagrangian multiplier test, and its correlation with independent variables by the Hausman specification test.

\footnotetext{
${ }^{6}$ As the contribution rate to the society is calculated on the basis of monthly remuneration, we do not use a wage rate (e.g. hourly wage) in our empirical analysis.
} 
33. The specification of the model takes two steps. In the first step, if the Breusch-Pagan Lagrangian multiplier test indicates there is unit-specific residual (in our analysis, the society-specific residual), we have to reject the pooled OLS model, and should apply one of the other two models. In the second step, if we find unitspecific residual is uncorrelated to independent variables by the Hausman specification test, we should apply random-effects model. If there is correlation, the fixed-effects model is the most plausible model.

\section{Empirical Results}

\subsection{Employers' contribution to Society-managed Health Insurance}

34. Figure 4 and 5 shows the distribution of contribution rate to health insurance societies and average monthly remuneration of regular employees covered by the insurance. Figure 6 shows the scatter plot between the contribution rate and log of average monthly remuneration. Based on the scatter plot, it is not quite clear whether the employers' contribution rate has a negative impact on wages.

\section{[Figure 4: Distribution of Employers' Contribution Rate to Health Insurance]}

[Figure 5: Distribution of Average Monthly Remuneration of Employees]

[Figure 6: Employers' contribution rate of health insurance and monthly average remuneration]

35. Table 1 shows the results of our estimation. By the Breusch-Pagan test and the Hausman test, we now know ex post facto that we should apply the fixed-effects model in this case. It means that there are unit-specific residuals of each health insurance society and the unit-specific residuals are correlated to independent variables.

[Table 1: Estimates of Equations of Average Remuneration and Employers' Contribution to Health Insurance]

36. The fixed-effects model suggested the $1 \%$ increase of employers' contribution rate to health insurance society result in about $1 \%$ reduction of the wage. It is also 
statistically significant. In other words, the incidence rate of employers' contribution on the wage is $100 \%$.

37. Interestingly, the dummy variable for changes in slope coefficient shown in the row "employer's contribution rate (\%) '97-'01 dummy" is also statistically significant, and takes a positive value (0.003). We put this variable to evaluate the impact of the raised co-payment in 1997. Based on this result, it seems reasonable to suppose that the change of the co-payment rate in FY1997 reduced the attractiveness of the benefit by society, and the insured persons have given lower evaluations on their employers' contributions to the society. Consequently, the $1 \%$ increase of employers' contribution rate results in $0.9 \%(=-0.0012+0.003)$ reduction of the wage since then.

\subsection{Employers' contribution to Long-term Care Insurance}

38. Figure 7 and 8 shows the distribution of contribution rate to long-term care insurance and average monthly remuneration of the regular employees, who are aged 40 and over and covered by the insurance. Figure 9 shows the scatter plot between the contribution rate and a log of average monthly remuneration. The scatter plot shows a clear negative relationship between the employers' contribution rate and the average wage remuneration.

[Figure 7: Distribution of Employers' Contribution Rate to Long-term Care Insurance]

[Figure 8: Distribution of Average Monthly Remuneration of Employees]

[Figure 9: Employers' contribution rate of long-term care insurance and monthly average remuneration]

39. The next table shows the results for the employers' contribution to the longterm care. The Breusch-Pagan test and Hausman test suggested that there are unitspecific residuals but the coefficients that are estimated by random-effects model and fixed-effects model are not the same. It indicated we should apply the fixed-effects model. 
[Table 2: Estimates of Equations of Average Monthly Remuneration and Employers' Contribution to Long-term Care Insurance]

40. Contrary to the clear negative relationship shown by figure 7 , the coefficient of the employer's contribution rate in the fixed-effects model is not statistically significant. It implies that the employers' contributions to long-term care insurance would not result in the wage change and employees do not regard the employer's contribution as a counter value of the long-term care.

41. This statistical insignificance may be caused by our initial assumption that the total contribution rate is shared in the same proportion of the health insurance by employers. Thus, we also applied the assumption that the contribution is shared equally by the employer and the employees for the estimation, however, the results, including the selection of the model, were the same.

\subsection{Discussion}

42. While Tachibanaki and Yokoyama (2001) concluded that the employers' contributions to social security in Japan are not shifting back to their employees, our empirical results suggested the opposite; the employers' contributions to health insurance society are shifting back to their employees. Where does this difference come from?

43. The variable of employers' contribution used by Tachibanaki and Yokoyama (2001) was the aggregated level of the contributions to the entire social security (e.g. pension, health insurance, unemployment insurance and work injuries insurance) by 10 industries for 27 years. On the other hand, we used the health insurance society data sets, which are at micro level. Because of the nature of society-managed health insurance, its budget must be balanced within society on the annual basis, and employees are more likely to realise that the employer's contribution is a counter value of their benefits compared with the other social benefits like pension benefits. Additionally, the existence of sickness allowance makes a strong relationship between the benefits and the contributions. 
44. Interestingly enough, our estimation of the incidence of employers' contributions to long-term care insurance failed to show that the contributions were shifting back to employees. A plausible explanation is that the employees aged 40 and over are not able to realise the employer's contribution as a counter value of long-term care services, because the majority of beneficiaries of long-term care insurance are the very elderly. Nonetheless, another explanation would be that the wage is still in the adjustment process and the two year panel data could not well capture this process, because only two years have passed since the introduction of long-term care insurance.

45. Based on our results, the statistically significant evidence of shifting back observed in society-managed health insurance may gradually deteriorate in the future. Actually, the dummy variable to allow for difference in slope suggested that the wage reduction relative to the employers' contribution rate became slightly smaller after the raise of co-payment rate in FY1997. Moreover, although our data set does not cover, the government raised again the co-payment rate of the Society-managed Health Insurance from $20 \%$ to $30 \%$ in FY2003.

46. On top of that change, as we explained in section 2.2, the contributions to society-managed health insurance are not only for covering the cost of the medical services within a health insurance society but also paying the assessed contribution to the health service system for the aged. This assessed contribution to the health service system has increased constantly as the population has aged. If this trend continues, the employees will start realising that the contributions to society-managed health insurance are a kind of income tax, and the shifting back to their wage will be diminished gradatim.

\section{Concluding Remarks}

47. Using the society-managed health insurance data, which is cross-sectional time-series and covers 1,670 health insurance societies for seven years, we found for the first time in Japan that majority of the employer's contribution to health insurance is shifting back onto the employees in the form of wage reduction. On the other hand, 
we can not find such evidence for the contribution to long-term care insurance using a two-year panel data set.

48. The difference between health insurance and long-term care is likely to be caused by the difference of the nature of two insurances. In terms of society-managed health insurance, the employees realise the very strong linkage between their benefits and contributions, and therefore the parameter $q$ in the theoretical model is close to 1 . It means the employees may agree to reduce wages in line with the increase of employer's contributions to health insurance society. Our empirical result supports this theoretical prediction.

49. Contrary to society-managed health insurance, the contribution paid by insured people aged 40 and over and their employer is not closely related to long-term care services, as most of the benefits are used by the very elderly. Thus, the employees regard the contributions as a kind of income tax, and the parameter $q$ in the theoretical model would be very small. This may well explain why we could not observe the incidence of contributions in terms of long-term care insurance.

50. The extent of the incidence of employers' contributions to social security in the form of wage reduction depends not only on the elasticity of labour supply/demand, but also on how employees value the contribution relative to social security benefits they enjoy. As the population is rapidly ageing, the apparent employers' contributions rate has been increased; however, the real rate may be different from the statutory rate depending on the nature of social insurance.

\section{Acknowledgments}

This paper was originally prepared for presentation at the 16th Annual Trio Conference in Tokyo, December 8th and 9th, 2003, supported by NBER-CEPRTCER-RIETI. This paper owes much to the thoughtful and helpful comments made by the discussants, Takero DOI and John PIGGOTT, and other conference participants, especially Takeo HOSHI and Yasushi IWAMOTO. But responsibility for the text with any surviving errors rests entirely upon the authors. 


\section{References}

Anderson, P., and B. Meyer [2000]

"The Effects of the Unemployment Insurance Payroll Tax on Wages, Employment, Claims and Denials," Journal of Public Economics, vol.78:81-106.

Gruber, J., and A. B. Krueger [1991]

"The Incidence of Mandated Employer-provided Insurance: Lessons from Workers' Compensation Insurance," D. Bradford (edited), Tax Policy and the Economy, vol.5, National Bureau of Economic Research.

Gruber, J. [1997]

"The Incidence of Payroll Taxation: Evidence from Chile," Journal of Labor Economics, vol.15, no.3, pt2:s72-101.

Filer, R., D. Hamermesh and A. Rees [1996]

The Economics of Work and Pay, Haeper Collins.

National Federation of Health Insurance Societies (Kenporen) [1997-2002]

Present Status Report on Society-managed Health Insurances (Kenko Hoken Kumiai no Gensei).

[2001-2002]

Annual Report on Society-managed Health Insurance (Kenko Hoken Kumiai Jigyo Nenpo).

Summers, L. [1989]

"Some Simple Economics of Mandated Benefits," American Economic Review, Paper and Proceedings 79(2):177-183.

Tachibanaki, T., and Y. Yokoyama [2001]

"The Estimation of the Incidence of Employer Contributions to Social Security in Japan," KIER Discussion Paper, no.528. 


\section{Figures and Tables}

Figure 1: Social Security Revenue in Japan by source, FY1980-2001 as a percentage of GDP

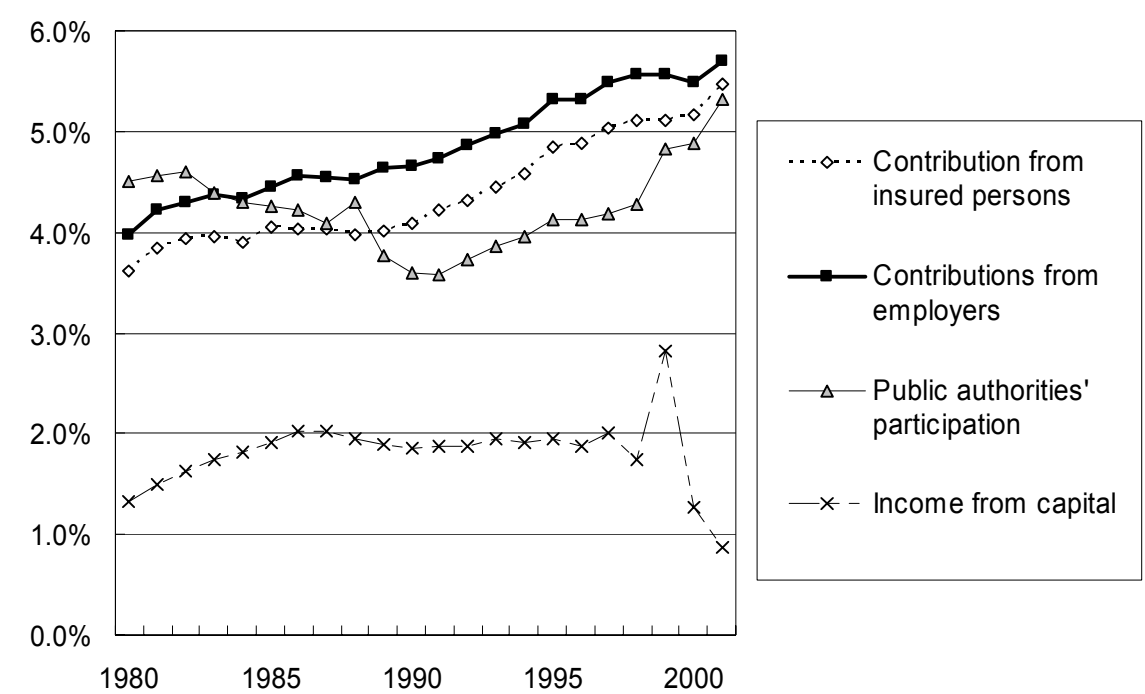

Source: National Institute of Population and Social Security Research (2003) The Cost of Social Security FY2001

Figure 2: Incidence of Social Insurance Contribution

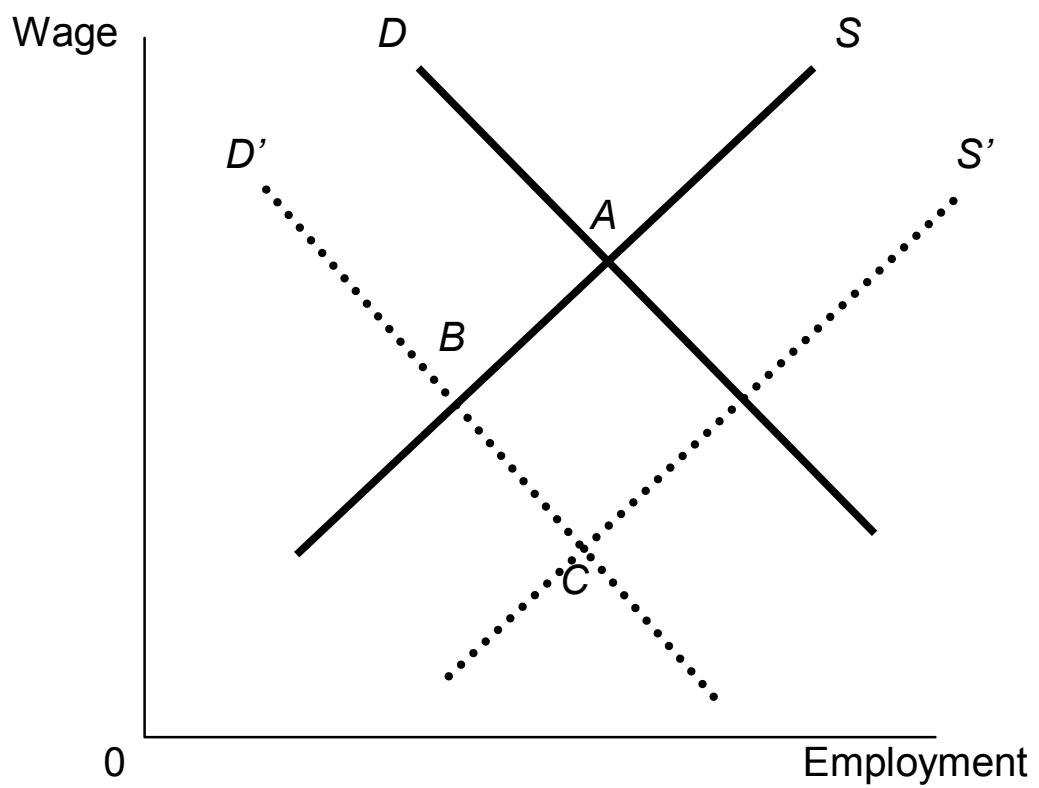


Figure 3: Major Public Health Insurances in Japan

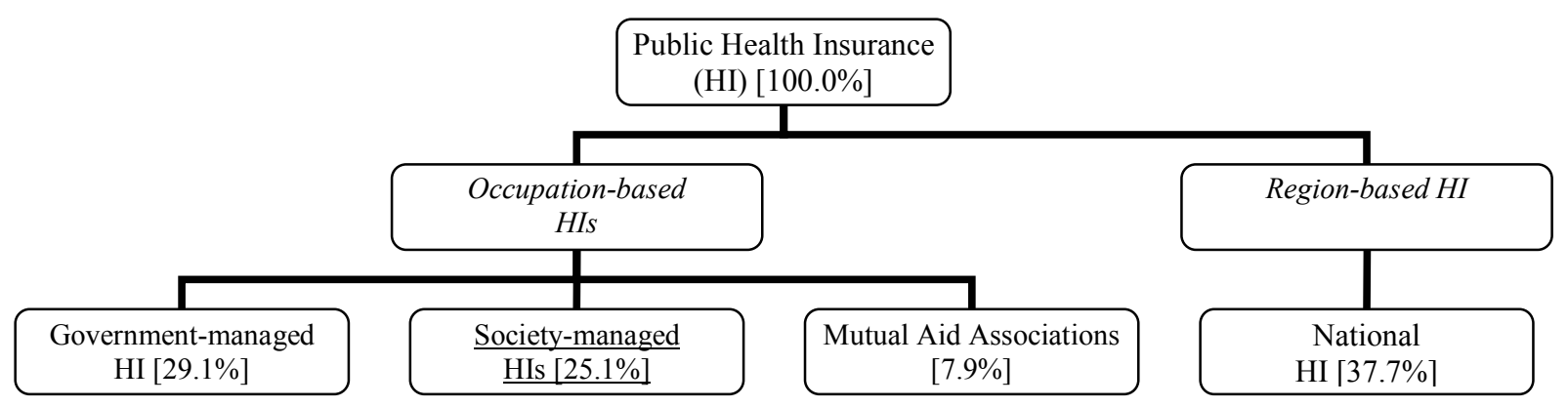

Note: the number in the parenthesis shows the share of the insured by each health care insurance in 2002 . As the seamen's' health insurance and day-labourers health insurance, which share of the insured is only $0.2 \%$, are not included in the figure, the sum of each share in the figure is not equal to $100 \%$.

Figure 4: Distribution of Employers' Contribution Rate to Health Insurance (seven-year pooled data: FY1995-2001)

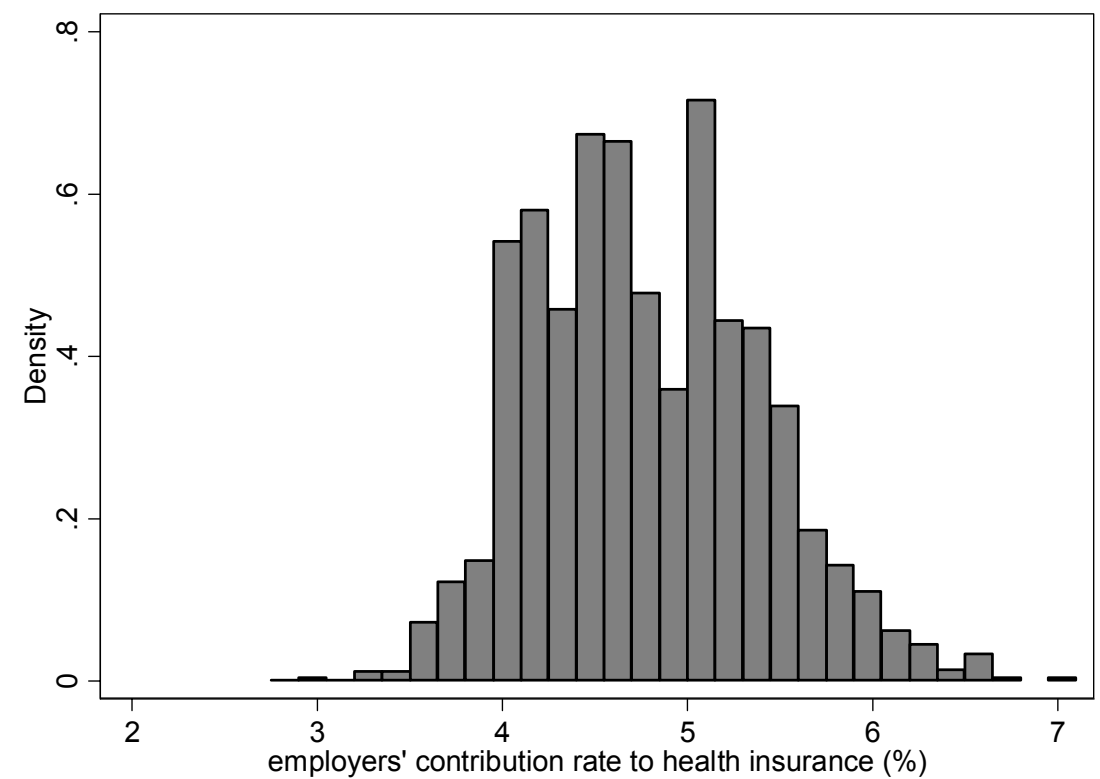

Source: Authors' calculation based on National Federation of Health Insurance Societies (1996-2002) 
Figure 5: Distribution of Average Monthly Remuneration of Employees Covered by Health Insurance (seven-year pooled data: FY1995-2001)

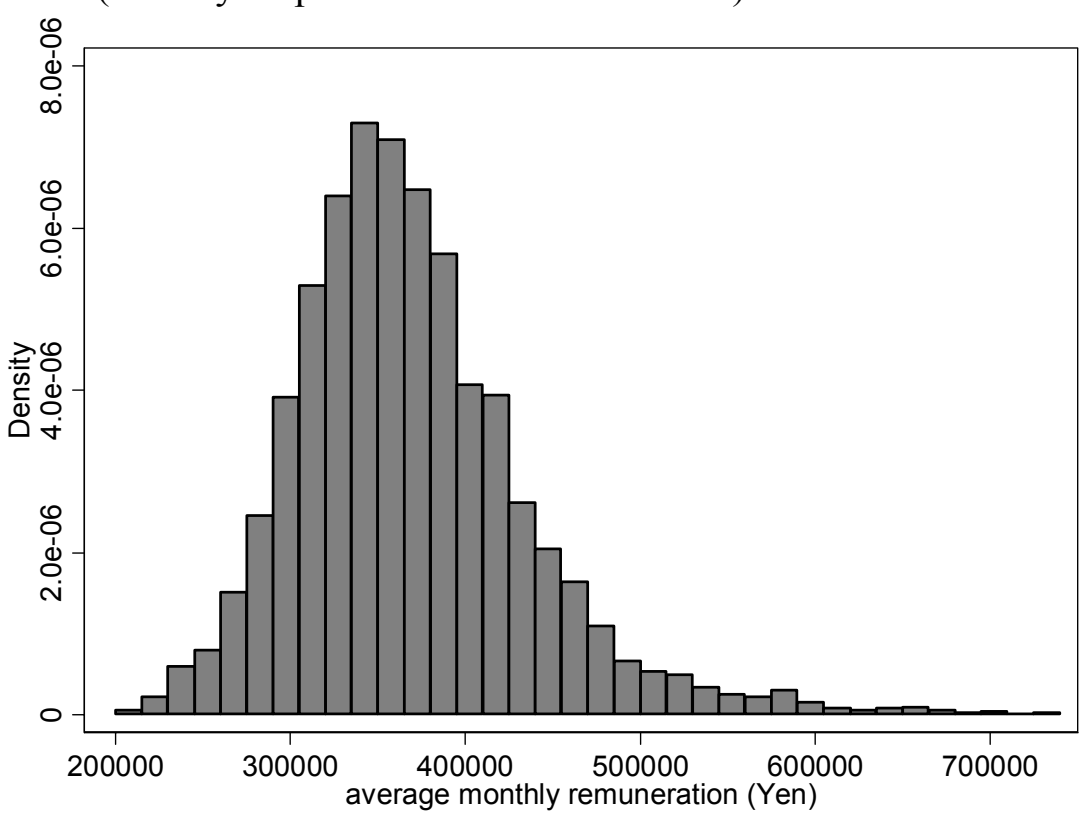

Source: Authors' calculation based on National Federation of Health Insurance Societies (1996-2002)

Figure 6: Employers' contribution rate of health insurance and monthly average remuneration (seven-year pooled data: FY1995-2001)

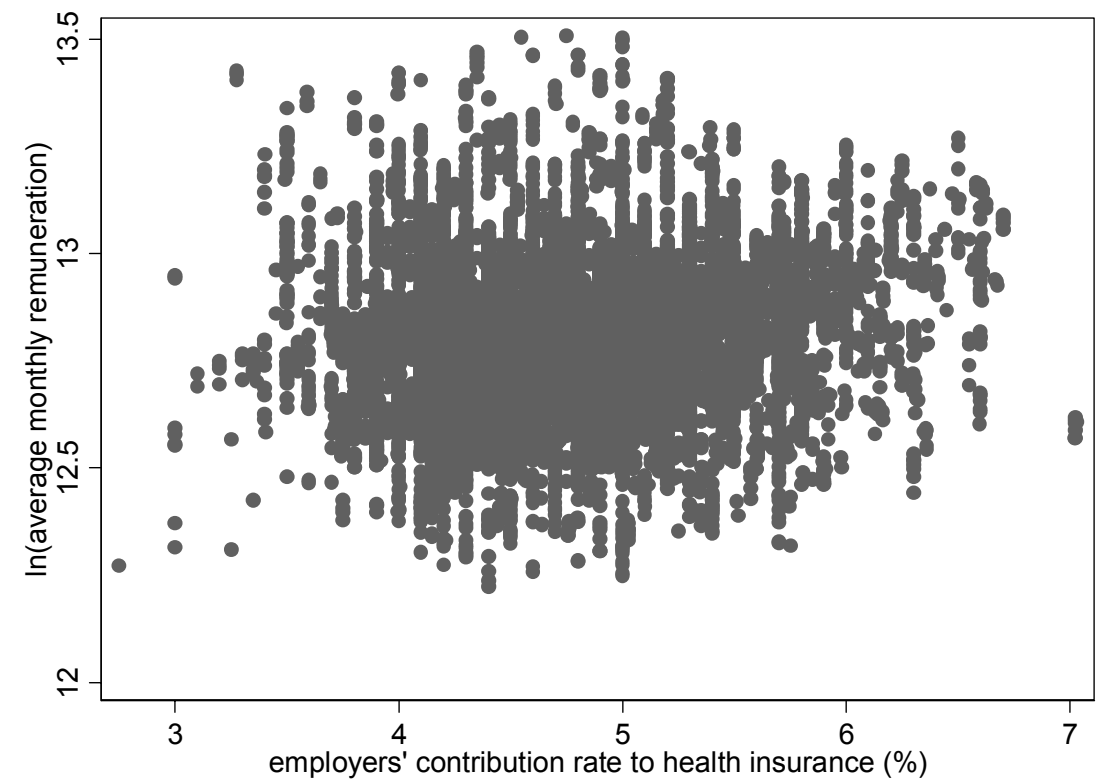

Source: Authors' calculation based on National Federation of Health Insurance Societies (1996-2002) 
Figure 7: Distribution of Employers' Contribution Rate to Long-term Care Insurance (two-year pooled data: FY2000-2001)

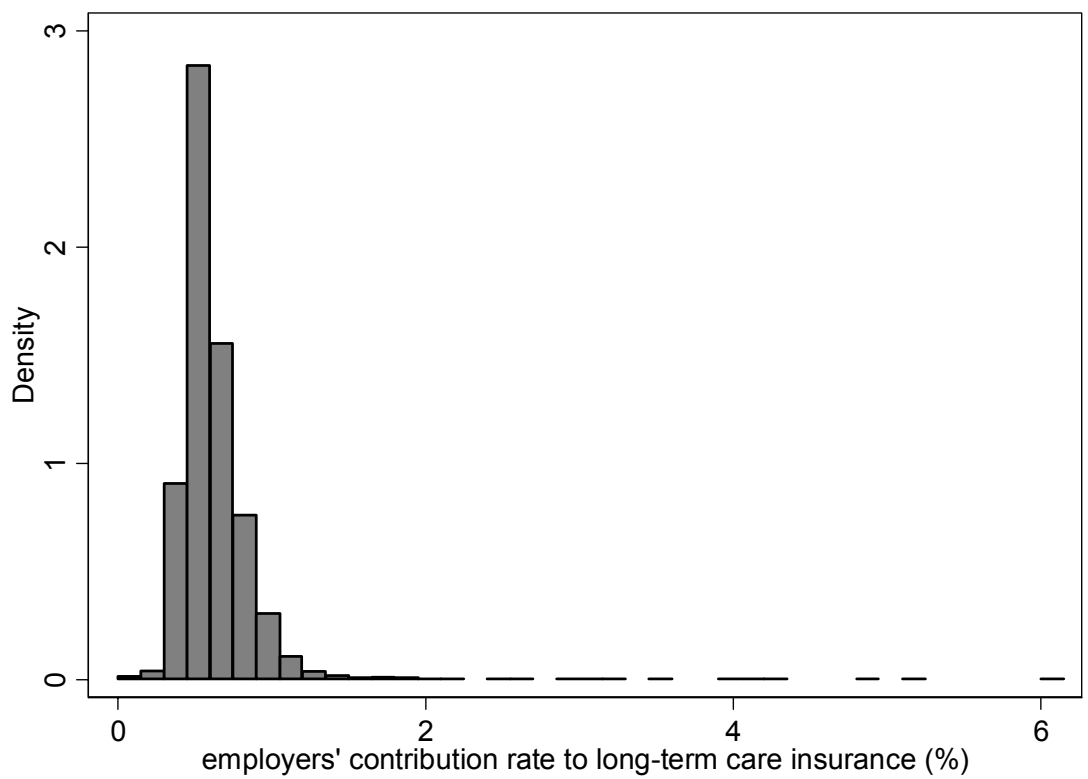

Source: Authors' calculation based on National Federation of Health Insurance Societies (2001-2002)

Figure 8: Distribution of Average Monthly Remuneration of Employees Covered by Long-term Care Insurance (two-year pooled data: FY2000-2001)

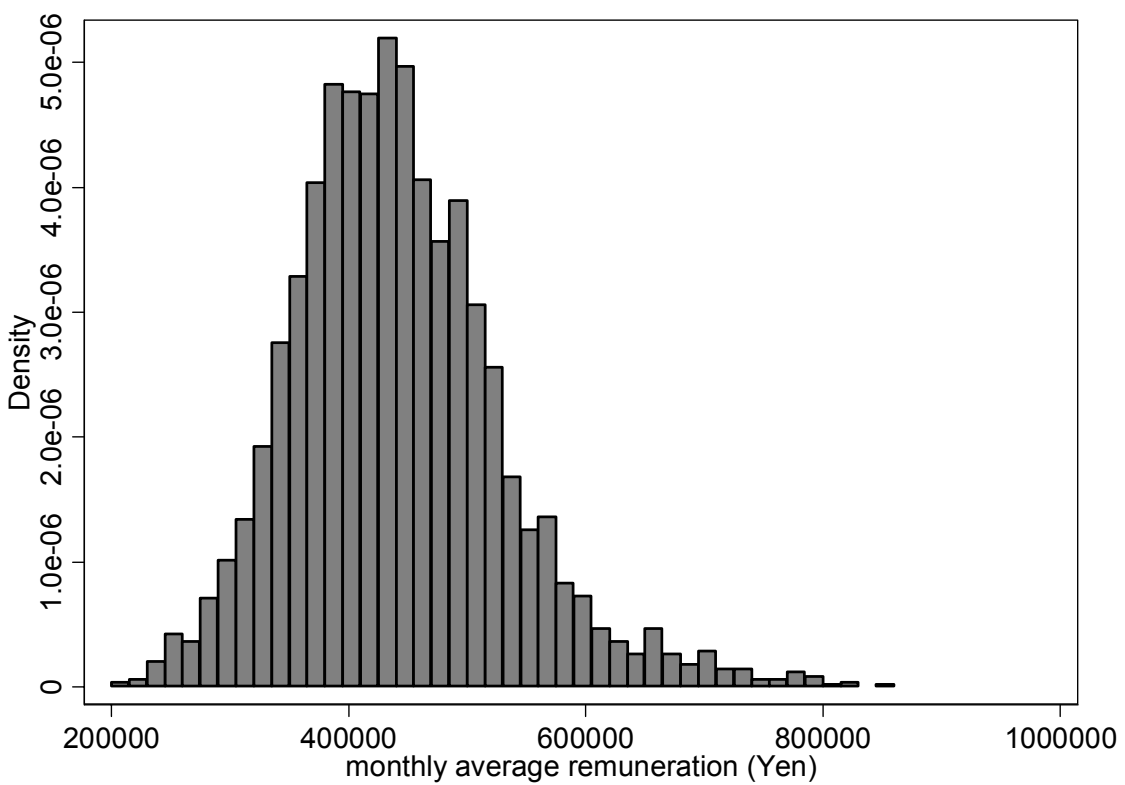

Source: Authors' calculation based on National Federation of Health Insurance Societies (2001-2002) 
Figure 9: Employers' contribution rate of long-term care insurance and monthly average remuneration (two-year pooled data: FY2000-2001)

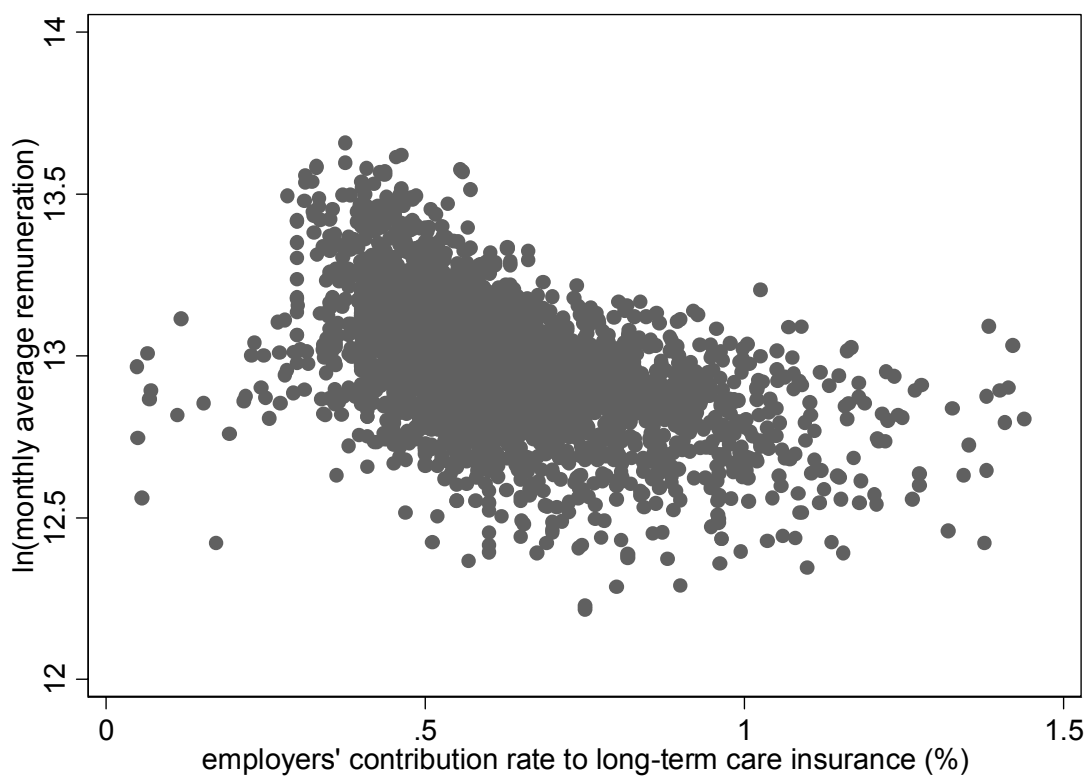

Source: Authors' calculation based on National Federation of Health Insurance Societies (2001-2002) 
KOMAMURA \& YAMADA: WHO BEARS THE BURDEN OF SOCIAL INSURANCE?

(the 16th Annual NBER-CEPR-TCER Conference, December $8^{\text {th }}$ and $9^{\text {th }}, 2003$ )

Table 1: Estimates of Equations of Average Remuneration and Employers' Contribution to Health Insurance

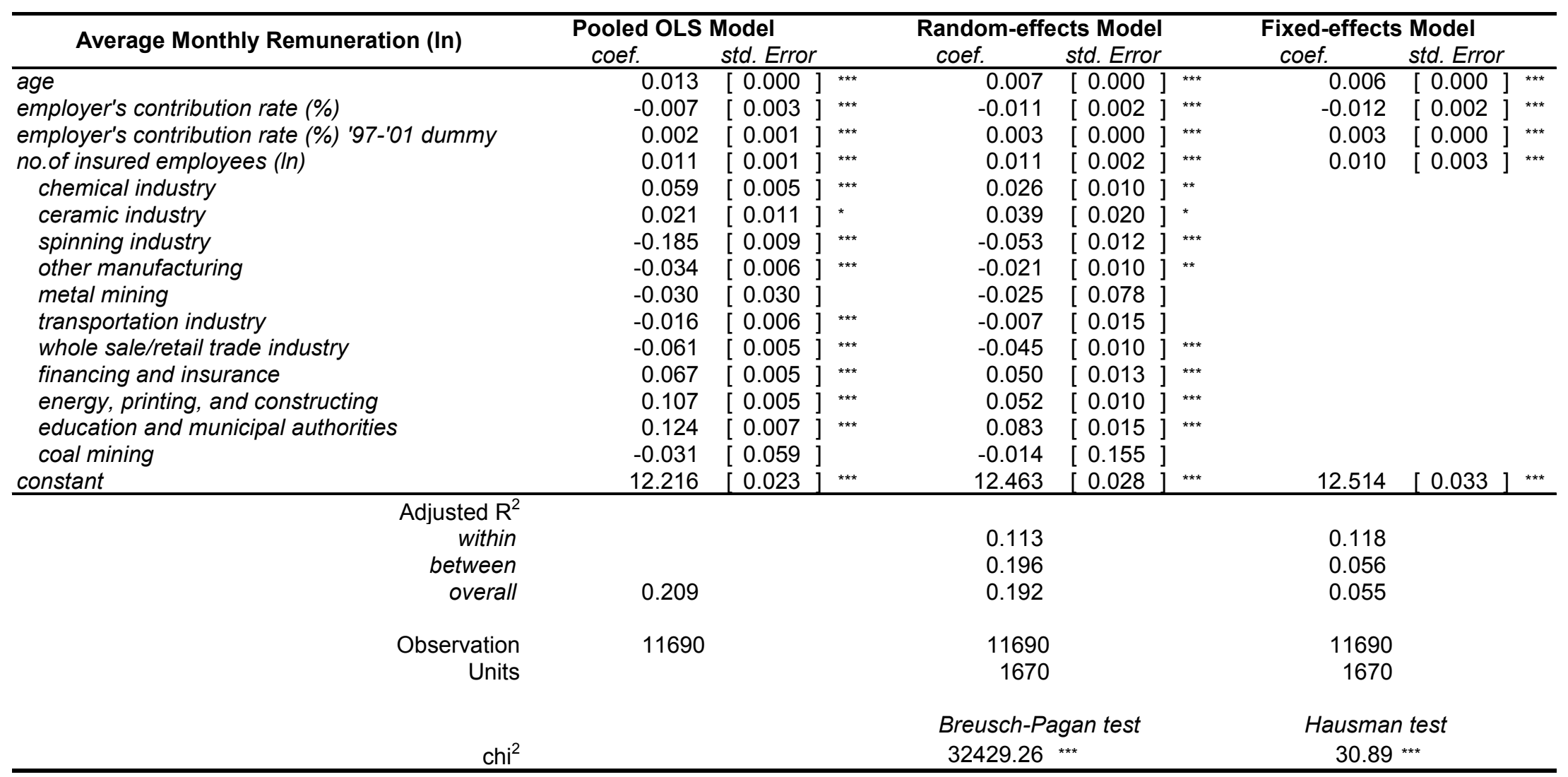

$p^{*}<10 \%, p^{* *}<5 \%, p^{* * *}<1 \%$

Source: Authors' calculation based on the National Federation of Health Insurance Societies (1996-2002) 
KOMAMURA \& YAMADA: WHO BEARS THE BURDEN OF SOCIAL INSURANCE?

(the 16th Annual NBER-CEPR-TCER Conference, December $8^{\text {th }}$ and $9^{\text {th }}, 2003$ )

Table 2: Estimates of Equations of Average Monthly Remuneration and Employers' Contribution to Long-term Care Insurance

\begin{tabular}{|c|c|c|c|c|c|c|c|c|c|}
\hline \multirow{2}{*}{ Average Monthly Remuneration (In) } & \multicolumn{3}{|c|}{ Pooled OLS Model } & \multicolumn{3}{|c|}{ Random-effects Model } & \multicolumn{3}{|c|}{ Fixed-effects Model } \\
\hline & coef. & std. Error & & coef. & std. Erro & & coef. & std. Error & \\
\hline$\overline{a g e}$ & -0.003 & {$[0.001$} & $x^{* \star *}$ & -0.012 & 0.001 & ${ }^{* * *}$ & -0.018 & $\overline{[0.001]}$ & $\overline{\star \star \star *}$ \\
\hline employer's contribution rate (\%) & -0.144 & {$[0.011$} & $* * *$ & -0.005 & 0.002 & ** & -0.002 & 0.002 & \\
\hline no.of insured employees (In) & 0.001 & {$[0.003$} & & 0.001 & 0.003 & & -0.011 & {$[0.006]$} & ** \\
\hline chemical industry & 0.074 & {$[0.012$} & $* * *$ & 0.060 & 0.016 & $* * *$ & & & \\
\hline ceramic industry & 0.027 & {$[0.024$} & & 0.037 & 0.034 & & & & \\
\hline spinning industry & -0.168 & {$[0.020$} & $\star \star \star *$ & -0.098 & 0.024 & $* * \star$ & & & \\
\hline other manufacturing & -0.039 & {$[0.013$} & $* * *$ & -0.043 & 0.018 & ** & & & \\
\hline metal mining & -0.030 & {$[0.062$} & & -0.036 & 0.089 & & & & \\
\hline transportation industry & -0.042 & {$[0.013$} & $* * *$ & -0.041 & 0.018 & ${ }^{* *}$ & & & \\
\hline whole sale/retail trade industry & -0.075 & {$[0.010$} & $* * *$ & -0.069 & 0.014 & $* * *$ & & & \\
\hline financing and insurance & 0.091 & {$[0.011$} & $* \star *$ & 0.085 & {$[0.015$} & $* * *$ & & & \\
\hline energy, printing, and constructing & 0.114 & {$[0.011$} & $* * *$ & 0.098 & 0.015 & $* * *$ & & & \\
\hline education and municipal authorities & 0.146 & {$[0.015$} & $\star \star \star *$ & 0.155 & 0.021 & $* * \star$ & & & \\
\hline coal mining & -0.085 & {$[0.124$} & & -0.091 & 0.178 & & & & \\
\hline constant & 13.146 & 0.044 & $* * *$ & 13.419 & 0.047 & $* * *$ & 13.798 & {$[0.070]$} & $* * *$ \\
\hline Adjusted $R^{2}$ & & & & & & & & & \\
\hline within & & & & 0.063 & & & 0.101 & & \\
\hline between & & & & 0.172 & & & 0.012 & & \\
\hline overall & 0.228 & & & 0.171 & & & 0.012 & & \\
\hline Observation & 3286 & & & 3286 & & & 3286 & & \\
\hline Units & & & & 1643 & & & 1643 & & \\
\hline $\mathrm{chi}^{2}$ & & & & $\begin{array}{c}\text { Breusch- } P \\
1428.27\end{array}$ & gan test & & $\begin{array}{r}\text { Hausmar } \\
21.41\end{array}$ & test & \\
\hline
\end{tabular}

$p^{*}<10 \%, p^{* *}<5 \%, p^{* * *}<1 \%$

Source: Authors' calculation based on the National Federation of Health Insurance Societies (2001-2002) 
Appendix: Key Statistics of Data Sets

\begin{tabular}{|c|c|c|c|c|c|c|c|c|}
\hline & \multicolumn{4}{|c|}{ Health Insurance } & \multicolumn{4}{|c|}{ Long-term Care Insurance } \\
\hline & mean & std. dev. & $\min$ & $\max$ & mean & std. dev. & $\min$ & $\max$ \\
\hline average monthly remuneration (Yen) & 368680 & 67498 & 203681 & 734485 & 441350 & 89021 & 202452 & 854551 \\
\hline age & 39.878 & 3.571 & 22.900 & 54.000 & 40.555 & 3.400 & 24.600 & 53.200 \\
\hline employer's contribution rate (\%) & 4.775 & 0.607 & 1.5845 & 7.029 & 0.631 & 0.306 & 0.048 & 6.141 \\
\hline no.of insured employees & 8680 & 16821 & 24 & 231351 & 3939 & 7461 & 21 & 104804 \\
\hline chemical industry & 0.098 & 0.298 & 0.000 & 1.000 & 0.098 & 0.297 & 0.000 & 1.000 \\
\hline ceramic industry & 0.018 & 0.134 & 0.000 & 1.000 & 0.018 & 0.134 & 0.000 & 1.000 \\
\hline spinning industry & 0.027 & 0.163 & 0.000 & 1.000 & 0.026 & 0.159 & 0.000 & 1.000 \\
\hline other manufacturing & 0.072 & 0.259 & 0.000 & 1.000 & 0.074 & 0.261 & 0.000 & 1.000 \\
\hline metal mining & 0.002 & 0.049 & 0.000 & 1.000 & 0.002 & 0.049 & 0.000 & 1.000 \\
\hline transportation industry & 0.079 & 0.270 & 0.000 & 1.000 & 0.077 & 0.267 & 0.000 & 1.000 \\
\hline whole sale/retail trade industry & 0.148 & 0.355 & 0.000 & 1.000 & 0.148 & 0.355 & 0.000 & 1.000 \\
\hline financing and insurance & 0.128 & 0.334 & 0.000 & 1.000 & 0.129 & 0.335 & 0.000 & 1.000 \\
\hline energy, printing, and constructing & 0.132 & 0.339 & 0.000 & 1.000 & 0.134 & 0.341 & 0.000 & 1.000 \\
\hline education and municipal authorities & 0.054 & 0.226 & 0.000 & 1.000 & 0.054 & 0.225 & 0.000 & 1.000 \\
\hline coal mining & 0.001 & 0.024 & 0.000 & 1.000 & 0.001 & 0.025 & 0.000 & 1.000 \\
\hline $\begin{array}{r}\text { Year } \\
\text { Observation } \\
\text { Units }\end{array}$ & & $\begin{array}{r}\text { FY199 } \\
11 \\
16\end{array}$ & & & & $\begin{array}{r}\text { FY200 } \\
32 \\
16\end{array}$ & 001 & \\
\hline
\end{tabular}

Source: Authors' calculation based on the National Federation of Health Insurance Societies (1996-2002) 